\title{
Paradigm Shift in Responding to Drug Users and Addicts: From a Criminal Justice to a Public Health Approach
}

\author{
James F. Anderson ${ }^{1}$, Kelley Reinsmith-Jones ${ }^{2}$, Willie M. Brooks, Jr. ${ }^{3}$, Adam H. Langsam ${ }^{4}$ \\ ${ }^{1}$ College of Arts \& Sciences, Professor of Criminal Justice, East Carolina University, Greenville, NC, USA \\ ${ }^{2}$ School of Health and Human Performance, Associate Professor of Social Work, East Carolina University, Greenville, \\ $\mathrm{NC}$, USA \\ ${ }^{3}$ College of Liberal Arts \& Social Sciences, Assistant Professor of Criminal Justice, Savannah State University, \\ Savannah, GA, USA \\ ${ }^{4}$ College of Liberal Arts, Professor of Sociology, Northeastern State University, Tahlequah, OK, USA \\ Correspondence: James F. Anderson, Professor, Department of Criminal Justice, East Carolina Uni versity, Greenville, \\ NC, USA.
}

Received: February 27, 2017

Accepted: March 20, 2017

Available online: April 12, 2017

doi:10.11114/ijsss.v5i5.2349

URL: https://doi.org/10.11114/ijsss.v5i5.2349

\begin{abstract}
Recently, there has been a paradigm shift in the way Americans have come to view drug users and offenders, particularly those affected by the current opioid epidemic. Unlike crack, this epidemic has led to humanistic and compassionate responses to treating the addiction and processing its users. While once stigmatized, demonized, and punished as criminals, today opioid addicts are treated using the medical model. We argue that the new paradigm has ushered in a public health approach, rather than the traditional criminal justice response that brings negative offender processing with adverse consequences. In the end, we believe that the new approach will be effective in treating and reducing opioid use. However, both criminal justice and public he alth approaches should be applied.
\end{abstract}

Keywords: crack cocaine, drug war, epidemic, opioid addiction, paradigm shift, public health approach, criminal justice approaches

\section{Introduction}

Social observers, scholars, politicians, health officials, and criminal justice practitioners have noticed a paradigm shift in the nation's attitude and approach to viewing and processing drug addicts and offenders. But, what has caused this change? Maxfield and Babbie (2011) define a paradigm as a model that organizes understanding. Hagan (2014, p9) provides that "a new paradigm represents a new revolutionary schema with which to view reality." Kuhn (1970) succinctly stated that paradigms provide sets of beliefs that guide work or research in an area (also see Bachman, Schutt, $\&$ Plass, 2017). Paradigm shifts are exceedingly rare in criminal justice and when they occur, they bring unprecedented change and discovery. Some examples of paradigms that have occurred in criminal justice in the past fifty years include: the emergence of white collar or elite crime; broken windows theory; the Kansas City prevention patrol experiment; and the attack on positivistic criminology in the mid-1970s that shifted correctional focus from treatment and rehabilitation to punitive policy such as mandatory sentences, as well as an increase in the imposition of the death penalty (Seigel, 2015). To argue that a paradigm shift has occurred in the way society views drug addicts and offenders, suggests that we view them differently now than how we viewed them in the past, especially with respect to how we would wage another war on drugs and the casualties (e.g., destabilized communities, poverty, fatherlessness, disrepair) left in its aftermath. But, the question remains, what ushered in this new paradigm that affects how we see and process those who are affected by the new drug epidemic?

During the mid-1980s throughout the 1990s, the U.S. government declared and fought a war on the drug epidemic, but instead of directing its criminal justice arsenal at all forms of illegal drugs (including heroin and powdered cocaine), it targeted a cheap form of cocaine known as "crack" or "rock" that was disproportionately used and sold by poor minorities, namely African-Americans and Latinos (Messner and Rosenfeld, 2007). Consequently, the government in general, and the justice system in particular, mounted an aggressive campaign towards massive incarceration efforts 
whose aftermath (e.g., over 2.2 million prisoners are currently confined in traditional places of incarceration) can still be seen in correctional systems across the country (Payne, Oliver, \& Marion, 2016). In fact, some criminal justice experts argue that changes in law and justice policies better explain the current increase in the number of people in prison rather than the commission of more crime (The Sentencing Project, 2016).

Throughout the aforementioned decades, there were more arrests made than at any other time in the nation's history. As a result, recent efforts have been made to reform the justice system by calling for, in part, attempts to decongest overcrowded prisons by revisiting the cases of offenders who were charged under discriminatory and bias drug laws (Sentencing Reform and Corrections Act of 2016). This work addresses a neglected area of criminological research that explains why there has been a paradigm shift in the nation's approach to fighting the current drug epidemic using the medical model, rather than the criminal justice model. As such, this paper is divided into four parts. Part One revisits Frank Tannenbaum's dramatization of evil and Karl Marx's Conflict Theory. Part Two discusses crack cocaine as a criminal justice issue. Part Three presents paradigm shifts and changing views of drug offenders. Part Four addresses opioid addiction as a public health issue. In the final analysis, we argue that policy makers should use both criminal justice and public health strategies to reduce the spread of this epidemic.

\section{Revisiting Frank Tannenbaum's Dramatization of Evil and Karl Marx's Conflict Theory}

Being labeled an addict or offender can bring negative consequences. Both labeling and conflict theories can explain how this may occur. However, it is important to address the role the community and justice system plays in accomplishing labeling. More specifically, we examine Frank Tannenbaum's labeling theory and Karl Marx's conflict theory. We select labeling theory since it offers a micro-level explanation for being stigmatized and conflict theory because it addresses state authority, law creation, and disparities in power relations on the macro-level. Both provide critical perspectives for examining criminological and criminal justice subject matter (Brown, Esbensen, \& Geis, 2004). However, before presenting each theoretical argument, a discussion of labeling and conflict explanations are essential to provide context. First, labeling theory focuses on the interactions that people have with informal and formal institutions. More specifically, the theory holds that one's interactions with others can shape one's self-concept and affect one's behavior (Barkan, 2009). Informal institutions include: one's peers, family, school, church, and others. Formal institutions include the justice system (i.e., police, courts, corrections, and laws). The quality of these exchanges (from either informal or formal mechanisms) can determine whether one receives informal or formal labeling from the community or justice system, respectively (Barkan, 2009). For example, if the community labels a resident as a drug addict, and the person accepts this deviant self-image, it could cause irreparable harm that leads to more deviance or crime.

Becker (1963) argues that one's identity is a reflection of the definitions given by others of his behavior. Likewise, if a resident is processed by the justice system and receives a criminal label as a drug addict, he may experience identity transformation that leads to more crime. Some labeling scholars argue that formal processing makes arrestees reassess their personal identity. At the same time, others who are privy to the person's experiences with the justice system may reevaluate their own view towards the labeled person (Brown, Esbensen, \& Geis, 2004). Therefore, both types of labeling have been known to have dire consequences depending on the label received or the punitive actions taken by the state. Labeling theorists argue that labels can dramatically stigmatize (Goffman, 1963). Second, conflict theory posits that powerful groups use the law as a resource (along with other agencies in the justice systems such as police, courts, and corrections) to control powerless groups. As such, they criminalize the behaviors of powerless people and avoid bringing their own under criminal inspection (Michalowski, 1985). Consequently, conflict theorists view the creation and enforcement of discriminatory drug laws (along with a police occupation in minority communities that primarily targeted crack cocaine users instead of powdered cocaine users who were disproportionately affluent and white) as instructive in this regard.

\subsection{Frank Tannenbaum's Labeling Theory}

Tannenbaum (1938) discussed the separation that an individual experiences after being caught and labeled for violating the law. He argued the individual undergoes transference, whereby, he goes from seeing the act he committed as being evil to becoming evil himself. Moreover, when the community reacts to the label, it dramatizes the label given to the individual. Put differently, Tannenbaum held that the community's reaction to the label tags, defines, and identifies the person as the new evil. He argued the practice is destructive to the labeled individual's personal identity and self-image since it means that he will be ostracized by others in the community and will no longer be viewed as one of them, but now will receive a new tag as an "other." More specifically, Tannenbaum argued when tagging or making evil occurs, the person receiving the label becomes the "thing" that he is described as being. During this process, one's personhood is stripped away, and a "thing" is constructed to represent the person. Consequently, the community no longer sees the person, but rather, the thing that is labeled. To Tannenbaum, the community's reaction represents the first phase in the 
dramatization of evil, and it has the greatest impact on making the offender (also see Schram and Tibbetts, 2014) since the community imposed isolation or ostracism forces those persons who have been similarly labeled to congregate. As such, the culture that is created and emerges from this, allows those with the label to escape and have a degree of security. However, it also leads to more crime.

\subsection{Karl Marx's Conflict Theory}

Conflict theory is traced to Karl Marx. Marx's analyses of the economic structure of society, along with power-relations, and class differences fit well with labeling theory. Nevertheless, Marx argued the owners of the means of production control other aspects of society, thus allowing them to maintain the status quo. He argued that powerful groups in society use their power and authority to control powerless groups by maintaining the existing arrangements. To some conflict theorists, this includes controlling formal agencies of social control such as: police, courts, corrections, and criminal laws. Because of this, these scholars are concerned with whether behaviors that become criminalized are targeted by formal agencies of social control. They are also critical of the power-relations that determine which behaviors become criminalized (Benard, 1981; also see Michalowski, 1985). In fact, conflict theorists argue that the powerful make the law without acquiring a consensus from others in society. They view the law as a political tool used by those in power to protect their economic and political interests (Lynch and Groves, 1989). More importantly, conflict scholars argue the law is used to impose labels on powerless groups. Some conflict scholars even suggest that the imposition of criminalization of certain behavior must appear to reflect a conflict between those with power and those without it (Jenkins, 1984).

\subsection{The Advent of Crack Cocaine and the Social-construction of Crack-fiends, Crack-heads, Crack-hoes, Crack-babies, and Super-predators}

The recession of the 1980s adversely affected all Americans. However, for minorities living in urban areas, the double digit unemployment level was devastating to their well-being and existence. In fact, economists report that the unemployment rate for blacks was more than twice the level for their white counterparts (Shank and Haugen, 1987). Sociologists provide that most cities were impacted by the fact that manufacturing jobs had been declining since the 1970s, but there was job growth and development in technological and service industries in the suburbs or areas occupied mostly by educated whites. These scholars argue that this economic restructuring did not "trickle down" to unskilled minorities in urban areas (Fagan, 1996; Hagedorn, 1988; Wilson, 1996). Therefore, when crack cocaine emerged amidst abundant poverty, it offered the chronically unemployed, displaced workers and many young males the chance to work during tough economic times by joining the drug market.

The media constructs images that sustain themselves as concrete realities to many Americans and others around the world (Potter and Kappeler, 1999; Donziger, 1999). This is revealed through media outlets such as television programming, newspapers, talk radio, networks such as $C N N$, MSNBC news, FOX news, the BBC and other mediums. However, the reality of crime in America is that the media can gravely distort reality and provide consumers (e.g., viewers) with images of a false narrative (Surette, 1995, 1998; Reinarman and Levine, 1989; Walker, 1998). For example, in the 1980s, the television show Cops, a reality-based, law enforcement show, presented weekly broadcasts of police activities in drug ridden minority communities across the nation. More specifically, Cops presented police fighting the war on drugs by chasing crack-fiends, crack-heads, crack hoes, and drug dealers. As this occurred, some justice scholars and politicians (researched and campaigned on law and order, respectively) began to refer to crack addicts and drug dealers as sociopaths, moral degenerates, as well as super-predators who destabilize and contribute to lawless communities (Bennett, DiluLio, \& Walters, 1996). Moreover, Cops and local news programs nationwide, presented viewers with negative images of poor minorities strung out on crack, along with countless reports of drug shootouts (deals gone bad), crack-hoes who exchanged sex for drugs to either feed their sex drive or drug addiction, crack-hoes who gave birth to 375,000 (fictitious and grossly exaggerated) crack babies who drained the health system because of neurological and developmental problems, rival gang wars over drug turf, and many untimely deaths (Hendricks and Wilson, 2013; Risser et al., 2006; Walker, 1998).

These negative images and presentations constructed a false narrative that became entrenched (and believed) by vie wers across the nation and globe (Reinarman and Levin, 1989). This also included many hard working people who lived among those who participated in the drug trade. Labeling theorists argue that the consequence of these images and labels made many people view drug addicts and offenders as sub-humans who deserved any punishment the justice system meted out on them. Furthermore, since these presentations were packaged, pre-packaged, and masked under the guise of a nation at war, viewers were introduced to paramilitarized policing tactics where police departments used SWAT teams and semiautomatic weapons to reclaim neighborhoods or terrain that had been seized by thugs, super-predators, and other enemies of the state. During these telecasts, viewers were routinely shown images of minority males handcuffed, manacled, and placed on bended knees as they were rounded up, interrogated, arrested, and 
transported to local police departments for booking. While these events occurred in the 1980s and 1990s amidst the crack cocaine epidemic, news critics argued that the media often provided a distorted view of the actual amounts of crimes that were committed, as well as disseminated false information regarding the pervasiveness of violent crimes (Surette, 1998; Donziger, 1996). Similarly, other news media scholars provide that after examining several local and national news outlets, they discovered a disproportionate amount of space, $25 \%$ and $13 \%$, respectively, devoted to covering news about crime and law enforcement compared to other news stories (Beirne and Messerschmidth, 1995). They report that this amount of coverage negatively impacts the perceptions of people who consume news information. More specifically, viewers came to believe that more crime in general, and violent crime in particular, was being perpetrated in the nation's streets. Consequently, because of this socially constructed reality, viewers called for more punitive actions to be used against those they had been led to believe engaged in violent crimes.

\subsection{Communities under Siege}

During the drug war of the 1980s and 1990s, media outlets, scholars, as well as politicians reported that lower class minority communities were besieged with drugs, "gang-bangers," killers, rapists, and other dangerous predators. In fact, John DiluLio coined the phrase "super-predators" to refer to young inner-city gang bangers who sold crack cocaine, used extreme violence, and lacked a moral conscience (Bennett et al., 1996). He argued that because they were not reared by loving or responsible parents, they lacked a moral compass. They were remorseless and impulsive, often terrorizing their own neighborhoods by making residents feel their community was under siege. DiluLio also stated that "a new generation of street criminals is upon us -- the youngest, biggest, and baddest generation our society has ever known" (Bennett et al., 1996). Perhaps even more devastating, DiluLio warned that young, male, predominantly black "super predators" would unleash a national crime wave on society in never before seen measures. As a result, nearly every state expanded its legal system to certify children and try their cases in the adult system. Consequently, many young teenagers received severe sentences such as life imprisonment without the possibility of parole. In addition, media experts reported that news organizations accepted DiluLio's theory and began constructing and presenting powerful images of crack cocaine as a highly addictive drug that destroys communities by robbing its youths of their promise. For example, the untimely death of Len Bias (a superstar basketball player from the University of Maryland), was instructive in this regard because shortly after he was drafted by the Boston Celtics, and had signed a contract with Nike, he overdosed at a party while smoking crack cocaine (Donziger, 1996). Despite this, none of the negative images were more effective than those of young sociopathic teenagers committing unspeakable violence in their own communities.

DiliLio, along with many politicians, capitalized on the negative imagery and used the super-predator theory to predict future crimes in minority neighborhoods. Media outlets, especially those reporting the daily news, led with stories using negative images and destructive presentations. Thus, they reported on poverty stricken neighborhoods as crack ridden battle zones where the people such as the elderly, some young, and a few wage earners were held captives by violence and young super-predators. In doing so, scholars reported that the media helped to create and perpetuate the drug scare of the 1980s and 1990s owing to its coverage and political rhetoric (Donziger, 1996). Moreover, the negative images presented by the media on nightly news programming justified the use of paramilitary tactics by police in their efforts to confront drug addiction, eliminate the sale of crack cocaine, and ultimately win the war on drugs. Unfortunately, these news and information sources failed to contextualize poverty, unemployment, joblessness, and living life as a member of the inner-city permanent underclass, but instead, they called for more punitive criminal justice, rather than medical or public health solutions (Reinarman and Levine, 1989).

\section{Crack Cocaine Use as a Criminal Justice Issue}

In the U.S., drugs have always been used as a source of the crime problem (Walker, 1998; Tonry and Wilson, 1990). Experts argue that drugs were linked to high rates of murders in the 1980s, gang violence, and growing prison populations. Therefore, as the war on drugs was waged during the 1980s and 1990s, the issues of crime, crack cocaine, and community fear were viewed as criminal justice matters that demanded swift governmental responses, namely in the forms of expanded use of police and other criminal justice interventions. As such, critics as well as historians argued that crack cocaine may have singlehandedly been responsible for the explosion of incarceration among African-Americans and Latinos. For example, shortly after the widely publicized death of Bias, then Speaker of the House, Tip O’Neil pressed Congress to impose mandatory sentences for anyone who possessed or sold crack cocaine. Since crack was the drug of choice among poor people, evidence existed at the time that revealed this measure would overwhelmingly impact minority communities as well as the federal prison system. Nevertheless, the bill was quickly passed into law (Donziger, 1996).

\subsection{The Public Safety Argument}

At the apex of the crack cocaine epidemic, the justification given for targeting minority communities with 
unprecedented policing presence was the public safety mandate. For example, a report from the Drug Enforcement Administration (1988) revealed that the crack cocaine problem was owned, organized, run, and controlled by minority groups. Some scholars report that African-American youths were disproportionately involved in the inner-city crack market (Messner and Rosenfeld, 2007). As such, the problem was viewed as a minority issue. In fact, the DEA's report suggested that the four major groups that controlled crack trafficking in the US included: Jamaicans on the East Coast and in Midwestern states; Haitians in Florida and Washington, DC; Dominicans in New York and Massachusetts, and black street gangs in Los Angeles who supplied the drug for the majority of the West Coast and western states (Tonry and Wilson, 1990; Drug Enforcement Administration, 1988). Moreover, scholars contend that with the increasing presence of crack in the inner-city areas, so too, came an increase in robberies, youth violence, threats, and other crime. Accordingly, along with the rise in the drug market, dealers realized they needed self-protection to secure their economic interests.

As large sums of monies were being made, dealers, and suppliers realized that they had to defend their business against robbers, competitors, and concerned community residents who might report them to police (Tonry and Wilson, 1990). Similarly, Messner and Rosenfeld (2007) reported that as the crack epidemic spread in the mid to late 1980s, it lead to increased danger involving many inner-city drug markets. Consequently, youth violence began to rise as young people armed themselves in record numbers (for self-protection) in these hostile environments. These areas invariably became prime recruiting grounds for gang members. This resulted in an arms race to better arm oneself against one's rival (Cork, 1999). As such, dealers and sellers instilled fear by inflicting unrestrained violence and intimidation on residents (young and old) not to get involved in reporting drug activity to police. Unfortunately, in many communities where crack was sold, residents were either accidentally shot or intentionally murdered as gangs performed their routine work of controlling the distribution of drugs.

\subsection{Mandatory Minimum Sentencing Policies}

One large weapon used in the criminal justice arsenal during the crack cocaine war was mandatory minimum sentences. These laws specified the minimum sentence one must serve. As such, they removed discretion from the courts to alter time served. The rationale behind mandatory minimum sentencing was to increase the certainty and severity of punishment for offenders convicted of serious charges (Messner and Rosenfeld, 2009). The National Corrections Reporting Program (NCRP) revealed that mandatory minimums were especially used on offenders who engaged in drug trafficking which resulted in extraordinary increases in the prison population. In fact, NCRP reported that over half (52\%) of the increase in prison admissions that occurred in the 1980s were primarily due to drug offenses. Moreover, Blumstein (1993) provided that the use of mandatory minimums to fight the war on drugs increased the severity of punishment for drug sales to a comparable level of time received by offenders who committed homicide. Criminal justice historians now agree that the amount of time received by African-Americans and Latinos for their involvement in the crack cocaine drug market was unparalleled in the history of American corrections.

\subsection{Massive Arrests}

Arrest statistics show that during the 1980s and 1990s, the number of incarceration (both on the state and federal levels) skyrocketed and its impact is still pronounced. For example, Blumstein and Beck (1999) and Mauer (1999) reported that by midyear 1991, 1,333,561 offenders were given a sentence to either a state or federal prison. This translated to an imprisonment rate of 468 prisoners per every 100,000 persons in the U.S. population. Comparatively, in 1980, 315,974 prisoners were in state or federal prisons at a rate of 139 per 100,000 people in the population. Penal experts argue that this fourfold increase in arrest rates within a 20 -year period created a crisis in the penal system in the areas of costs and overcrowding. More specifically, history reveals that as the number of inmates continued to grow from the $80 \mathrm{~s}$ and $90 \mathrm{~s}$, several constitutional issues (e.g., Eighth and Fourteenth Amendment) emerged regarding the problems and legality of the conditions of confinement that were created by overcrowding in jails, state and federal prisons. As such, prisoner rights advocates cite that at the end of 1998, state prisons were operating with inmate populations that averaged $113 \%$ (well) over their legal capacity. At the same time, federal prisons operated at 127\% (also) well over their legal capacity (Beck and Mumole, 1999). This occurred, despite the American Correctional Association advising prisons not to operate at a rate that exceeds $90 \%$ of their capacity.

\subsection{Status of Prison Overcrowding from the 1990s to 2015}

The growth of the prison population has shifted the focus of corrections from administering levels of punishment that offenders deserve to the necessity of risk management of dangerous populations (Feeley and Simon, 1992). Nevertheless, statistics reveal that at the end of 1996, 5.5 million Americans were under correctional sanction. Of these, 1.6 million were confined in jail or prison and the remaining 3.9 million people were placed under community supervision (an estimated 3.2 million on probation and .7 million on parole, respectively). What is more striking is that between 1980 and 1996, the number of adults placed on correctional sanction in the U.S., increased by $200 \%$ (BJS, 
1996, 1999). At the end of 2015, an estimated 6,741,400 Americans were under correctional supervision. Experts report that this represents the first time since 2002 that the correctional population had fallen below 6.8 million (Kaeble and Glaze, 2016). More specifically, they argue this decrease was the largest since 2010. This reveals that 1 in 37 adults in the U.S., was under some form of correctional supervision at the end of 2015. Moreover, by the end of 2015, the community supervision population $(4,650,900)$ dropped to its lowest level since $2000(4,564,900)$.

The number of persons under institutional corrections dropped in 2015 from 2,173,800 to the lowest level since 2004 at 2,136,600 (Kaeble and Glaze, 2016). BJS (2016) attribute the drop in the population of community supervision during 2015 to a decrease in the probation population which was down by 2 percent. Likewise, they view the decline in the incarcerated population in 2015 (down by 51,300 ) as primarily due to the decline in the prison population which is down by 35,500. Despite this, the Sentencing Project reports that the U.S. is the world's leader in incarceration with 2.2 million people in the nation's jails and prisons representing a 500\% increase over the last 40 years with changes in sentencing policy, not changes in crime rates primarily accounting for the increase (Walmsley, 2015). Consequently, the growth in the inmate population has caused court and correctional experts to seek community based programs to accommodate offenders who may be more appropriately sentenced to the community rather than to secure institutions, and for those returned back to the community after periods of incarceration. More specifically, some programs that have been used to divert offenders from institutional corrections include: shock incarceration (boot camps), halfway houses, residential programs, electronic monitoring, house arrests, and super intensive probation programs. Yet, offenders who have served institutional time may eventually be released and returned to their respective communities and placed on parole.

\section{Paradigm Shifts and Changing Views of Drug Offenders and Addicts}

Some experts argue that the current demand for accountability in the criminal justice system, shifts in public opinion about severe punishment given to nonviolent drug users, and the public's favorability towards alternative sanctions may have emerged because of the expensive costs associated with massive incarceration efforts, disproportional arrests of drug addicts, and overzealous prosecution of minority drug users. Today, most people in the general public, and healthcare advocates, support the idea that drug addiction is a disease that requires treatment instead of punishment, especially when drug abuse takes on a nonviolent nature. Since the crack cocaine war, public opinion and sentiment have changed with respect to how drug users and addicts are viewed and should be treated. For example, a Ridder/Braden opinion poll revealed that $59 \%$ of 500 potential voters in Colorado viewed drug addiction as a health issue compared with $11 \%$ who viewed drug addicts as criminals. The poll found that $75 \%$ of the respondents preferred more drug treatment, drug prevention, and educational programs to punitive criminal justice measures. Moreover, $80 \%$ of the respondents reported that treatment was an effective means to reduce drug-related crime while $60 \%$ of them felt that incarceration was an ineffective way to respond to people convicted of possessing small amounts of drugs (Survey on Drug Abuse and Drug Policy, 2001). Similarly, a national study by the American Civil Liberties Union using 2,000 adults found that $74 \%$ favored drug treatment and probation, rather than prison, for nonviolent illegal drug use. Moreover, $77 \%$ of the respondents believed that laws should be changed so that fewer nonviolent offenders receive a prison sentence. The study also revealed that $61 \%$ of the respondents opposed mandatory sentences for some nonviolent crimes (Alexander, 2001). In another national study, the U.S. Department of Justice surveyed 1,300 respondents about their attitude towards crime. The study revealed that $99 \%$ wanted convicted robbers to receive a prison sentence, $65 \%$ wanted offenders convicted of identity theft or counterfeiting sentenced to prison. However, the study found different sentiments when it came to drug users and drug offenders. For instance, the findings revealed very few respondents (18\%) believed that those convicted for the first time of simple drug possession should be sent to prison (Cohen, Rust, \& Steen, 2003). Moreover, a California study by the National Council on Crime and Delinquency (2004) that relied on a sample of 1,000 respondents revealed that $56 \%$ believed that the crime problem could be reduced if more offenders were given rehabilitation and re-educated in programs outside of prison. In this study, $67 \%$ embraced providing services to nonviolent drug offenders both in and out of prison (Krisberg, Craine, \& Marchiominna, 2004). Furthermore, in its study, the National Center for State Courts (2006) surveyed 1,500 respondents and found that $79 \%$ believed offenders could be rehabilitated, and $51 \%$ favored using alternatives to traditional punishment for nonviolent offenders. More specifically, $37 \%$ even suggested that alternative sentencing should be tried on some violent offenders, $56 \%$ felt that judges should have more discretion in sentencing, while only $36 \%$ of all respondents favored mandatory prison sentences.

Contemporary research on the public's attitude over use of punishment in general, and corrections in particular, show strong signs that it has become less inclined to support incarceration and harsh treatment. For example, a national poll conducted in 2012 revealed that Americans (both Democrats and Republicans) believe that there are too many people in the nation's jails and prisons. They also believe that the costs associated with confining nonviolent offenders such as drug users and addicts are too costly. In the end, the Pew study revealed that voters desire affordable and effective 
community alternatives to institutional corrections. Americans also support efforts designed to reduce long term sentences that non-violent offenders spend behind bars. The survey suggests that if offenders are given rehabilitation programs that include job training and substance abuse treatment, these efforts can prevent them from returning to a life of crime while freeing valuable bed space for violent offenders (Pew Charitable Trusts, 2012).

It is apparent to governmental officials and practitioners who worked in the justice system during the crack epidemic that today's drug users and addicts are treated and processed differently. In fact, Strand (2016) argues that lawmakers nationwide contend that with the current opioid epidemic, more resources should be redirected from massive incarceration efforts to more treatment and rehabilitation programs. More specifically, state lawmakers are examining the sheer numbers of drug addicts who would otherwise be sent to prison and other places of confinement and argue that states should offer treatment, rather than solely punishing offenders. They present a twofold argument. First, incarceration costs the justice system hundreds of millions annually. Second, the recidivism rates are higher for drug addicts who do not receive effective treatment and counseling while confined. Furthermore, many justice practitioners, especially police officers and correctional personnel, have concluded that warehousing addicted inmates is not the solution to this drug epidemic. Moreover, Grzelewski (2015) provides statistics with trends showing that opioid addiction is not likely to drop anytime soon. Consequently, many health experts, politicians, as well as justice officials believe that new and different views, along with creative solutions, are needed to address the opioid crisis. One idea that has emerged is that drug addiction is now viewed as a disease, rather than a crime. Though it seems rather simplistic, if accepted, it changes everything for addicts with respect to how they are vie wed, treated, and socially processed. As such, most jurisdictions around the nation are seeking treatment for addiction instead of punishment to reduce and eliminate this behavior. Experts are advancing the idea of creating effective treatment centers for addicts to cure their disease. This represents a paradigm shift from viewing drug addicts as dangerous predators who deserve institutionalized punishment by the criminal justice system for their involvement in drug use and crime to a compassionate approach to seeing addicts as people who suffer and struggle with a treatable and curable disease.

Labeling and conflict theorists view the current paradigm shift as a logical course of action for several reasons. First, because negative labeling leads to more crime, using the public health approach to address the opioid epidemic and by passing the criminal justice system increases the likelihood that addicts will not experience the same negative labels given to addicts who were involved in crack cocaine since the labels mean in many cases, offenders will be stigmatized after imprisonment and barred from pursuing conventional avenues to reintegrate and succeed in society. Second, conflict theorists view the paradigm shift towards compassionate treatment and understanding in the current epidemic unlike crack because now the users and addicts of opioids are disproportionately white, male, young and nonblack or Hispanic. As such, it is a drug crisis that has hit close to home since many users and addicts share the same physical characteristics as those in positions of power and authority with the ability to define drug addiction as a disease. Simply put, they may have more compassion for this group of addicts because they can identify with them. Consequently, lawmakers, politicians, educators, clergy, law enforcement personnel and others may also know someone or have family members who are negatively impacted by the opioid epidemic. Unlike crack cocaine which was primarily a lower class minority problem, the reach and magnitude of opioid abuse and addiction cuts across all race, class, and gender lines. Therefore, this may have facilitated the need to decriminalize addiction and address the matter as a public health issue rather than a criminal justice problem.

\section{Opioid Addiction as a Public Health Issue}

The public health system is responsible for protecting the safety of communities and improving its health via education, policy, research, and innovative programs to prevent injury and disease (Schneider, 2000). This includes responding to epidemics and pandemics, both of which describes the current crisis of opioid addiction and overdose. More specifically, an epidemic is the occurrence of more cases of disease than expected in a given area or among a specific group over a period of time (Dicker \& Coronado, 2006), as compared to a pandemic, which is an epidemic occurring globally or over a very wide area, crossing international boundaries and affecting large numbers of people (Last, 2001).

Experts estimate that each year in the U.S. between 70,000 and 100,000 people die from opioid overdose. They also stated that in 2010, illicit opioid overdose was the primary cause of death worldwide (United Nations Office on Drugs and Crime, 2012). While the U.S. makes up nearly half of all illicit opioid users globally, many developed and developing countries have witnessed significant growth in the use of nonmedical prescription opioids (United Nations Office on Drugs and Crime, 2011). Furthermore, medical experts report that opioid overdose has become the most prominent source of avoidable death among intravenous drug users (Degenhardt et al., 2011).

From 1995 to 2011, emergency room admissions, as well as substance abuse treatment admissions, experienced a tenfold increase linked directly to opioid use. Similarly, from 1997 to 2011, pharmaceutical sales of opiate drugs such as hydrocodone, methadone, fentanyl and morphine also reported an increase (Degenhardt et al., 2011). Medical experts 
reveal that this occurred after the American Pain Society declared pain as "the vital $5^{\text {th }}$ sign" and after support was gained from the Veteran's Health Administration in their national pain management strategy (National Pharmaceutical Council, 2001). Despite this, scholars consider 2010 as the peak year for the U.S. opioid epidemic (Kim, Windsor, \& Mareiniss, 2016). At this time, opioid painkillers were attributed to more than twice as many deaths as heroin and cocaine combined (U.S. Department of Health and Human Services, 2013). More specifically, an estimated 4,903 of 16,651 deaths were caused by opioids alone (Jones, Mack \& Paulozzi, 2013). Moreover, in 2014, an estimated 78 Americans died each day owing to an opioid overdose (U.S. Department of Health and Human Services, 2016).

Health officials report the opioid problem in America has reached the point of a public health crisis since opioid painkillers have accounted for more deaths than either suicides or motor vehicle accidents (Mc Donald \& Carlson, 2013). In fact, medical scholars reveal that opioids (including prescription opioid pain relievers and heroin) were the major factor in more than 28,000 deaths in 2014, with no less than half of all opioid overdose deaths involving a pres cription opioid. Moreover, since 1999, prescription opioids sales in the U.S. have nearly quadrupled (this has occurred without reports revealing any overall change in pain from patients) (U.S. Department of Health and Human Services, 2016). Furthermore, research by Muhuri, Gfroerer \& Davies (2013) revealed that nearly seventy-five percent of new heroin users reported abusing prescription opioids before trying heroin.

Some health officials report the most significant driving force behind the increase in opioid prescriptions began with a Purdue Pharmaceutical promotional plan that spanned from 1996 to 2000. During this time, its sales force increased from 318 representatives to 671, and its physician call list increased from approximately 44,500 to between 70,500 and 94,000 physicians (U.S. Government Accounting Office, 2003). During this campaign, Purdue encouraged the use of prescription opioids for non-cancer pain. This resulted in nearly a tenfold increase in OxyContin prescriptions for non-cancer pain. Statistics reveal the number of prescriptions dramatically increased from 670,000 in 1997 to 6.2 million in 2002 (U.S. Government Accounting Office, 2003). In the U.S. in 2013, medical providers wrote nearly a quarter of a billion opioid prescriptions, "enough for every American adult to have their own bottle of pills" (IMS Health, N.D.). Similarly, Lev and colleagues (2016) reported from 2002 to 2010, family medicine physicians accounted for the greatest proportion of opioid prescriptions and opioid-related fatalities. They also found that other healthcare professionals who prescribed outrageous numbers of prescriptions for opioids included: psychiatry, emergency medicine doctors, anesthesiologists, pain management physicians, and dentists. Added to this alarming finding, research emerged that suggested some professionals practicing in these health fields also personally abused prescription drugs (United Nations Office on Drugs and Crime, 2016). Notwithstanding, another major factor in the upswing of opioid prescriptions occurred in 1996 when the Federal Drug Administration labeled the prescription opioid OxyContin as nominally addictive and marketed it to generalist physicians to prescribe to patients for "moderate" pain conditions (Van Zee, 2009). Yet another finding that has generated concern is the inappropriate prescribing practices and opioid prescribing rates among Medicaid patients compared with those who are privately insured (U.S. Department of Health and Human Services, 2016).

Research finds that while men and women can experience pain equally, there are significant gender disparities. For example, women are at an increased risk for chronic pain and may actually experience more severe pain than their male counterparts (Bartley \& Fillingim, 2013); the occurrence of common forms of pain is higher among women than men (Fillingim et al., 2009), and women are more likely to report a greater variety of pain ailments, more severe pain, longer-lasting pain occurring more frequently, as well as more diffused pain (Hurley \& Adams, 2008). Some studies also report the existence of gender differences in response to pharmacological and non-pharmacological pain treatment (Bartley \& Fillingim, 2013). Some medical scholars argue that this may explain the higher rates of prescription opioid abuse among women. Furthermore, research studies in the U.S. as well as abroad reveal that women are just as prone (or even more) to abuse prescription drugs and are also more likely to be prescribed a drug that can be abused (Elkins, 2015).

Medical experts argue that the opioid crisis may also place some women at a higher risk of danger than others. For example, research reveals that during 2008-2012, more than a third of reproductive-aged women enrolled in Medicaid (along with more than a quarter of those with private insurance), received an opioid pain medication prescription for either hydrocodone, codeine, and or oxycodone which can cause fetal complications that produce an increased risk of neural tube defects (major defects of a baby's brain and spine); congenital heart defect, gastroschisis (a defect of a baby's abdominal wall); and neonatal abstinence syndrome (NAS) from exposure to medications such as opioids during pregnancy (U.S. Department of Health and Human Services, 2015). Moreover, every 25 minutes, a baby is born that suffers from opiate withdrawal, and is therefore at risk of developing (NAS) and other problems such as low birth weight and respiratory complications (National Institute on Drug Abuse, 2015). Medical experts argue that NAS can last as long as three months. It can also bring painful symptoms for a newborn that typically include: tremors, irritability, excessive crying, diarrhea, seizures, jitteriness, and other health-related problems (Kocherlakota, 2014). 
While adverse health care issues are prominent among adults and infants, prescription opioids are also commonly abused by youths. For example, in 2009, prescription painkillers were cited as the second most frequently used drug by high school students, while marijuana was the first (Johnston et al., 2011). In 2014, prescription drug abuse was at $12 \%$ among young adults between the ages 18-25 compared with $6 \%$ for youths between the ages of $12-17$, and $5 \%$ between the ages of 26 and above (National Institute on Drug Abuse; National Institutes of Health; U.S. Department of Health and Human Service, 2016). In addition, there were more than 1,700 youth deaths recorded owing to prescription drug (primarily opioids) overdoses (NIDA; NIH; DHHS, 2016).

Health experts agree that when used properly and as instructed, opioids are safe. However, they warn that prescription opioids become dangerous when misused, or when they are diverted from their prescribed source and taken by unintended users (Substance Abuse and Mental Health Services Association, 2016). Experts argue the latter is a growing problem in the U.S. More specifically, they argue that opioid diversion involves the purposeful deviation of a prescription drug from its intended path and is a crime that is mostly perpetrated in the forms of theft, doctor shopping, forged prescriptions, counterfeit drugs, and international smuggling (National Association of Drug Diversion Investigators, 2011). Studies show that instances of opioid diversion committed by health care personnel are eventually discovered after major incidents of outbreaks occur. In fact, Schaefer and Perz (2014) reported that in a ten year span, six diversion incidences were discovered that revealed a link to more than 100 infections and nearly 30,000 potentially exposed patients that involved injectable controlled substances. In addition, another type of opioid diversion occurs when patients use several physicians and pharmacies to acquire prescription medication. This is referred to as "doctor shopping." This practice reveals shocking statistics since an analysis of 146.1 million opioid prescriptions dispensed during 2008 showed that 1 in every 143 patients was able to obtain several prescriptions from multiple physicians. More specifically, it revealed that on average, 32 prescriptions were filled by 10 physicians. These drugs are later dispensed by the patient through other mechanisms (McDonald \& Carlson, 2013).

While prescription opioids seem to be the favorite choice among drug abusers, heroin use as well as heroin overdose deaths are also increasing. In fact, medical reports reveal that more than 10,500 people died in 2014 owing to a heroin-related overdose (U.S. Department of Health and Human Services, 2016). Moreover, of the 517,000 people who have been identified as being dependent on or abusers of heroin, 169,000 were new users (U.S. Department of Health and Human Services, 2016). Furthermore, demographical data reveal that between 2004 and 2013, there has been a 50\% increase in the number of males using heroin, and an alarming $100 \%$ increase among women users. Additionally, there has also been a $114 \%$ increase among non-Hispanic white users; and significant increases related to income. More specifically, there has been a 77\% increase in heroin use among those with a reported earned annual income of $\$ 20,000$ to $\$ 49,000$, and a $60 \%$ increase among households with a reported earned income of $\$ 50,000$ or more (U.S. Department of Health and Human Services, 2015).

Some scholars report that there are also special groups that are vulnerable to opioid abuse and overdose deaths. These groups are composed of people who have been recently released from prisons and/or patients who are newly discharged from addiction and treatment facilities. Where the first group is concerned, Merrall and colleagues (2010), reported that the first two weeks of post-release are the most critical for prisoners who die owing to drug use. However, other scholars argue that the risk of a drug related death has been found to be six times higher after three weeks of release with an elevated risk even in the fourth week (Ødegard et al., 2010). Despite this, Merrall and colleagues (2010) provided that the two primary reasons for this high risk are: (1) the prisoner's decreased tolerance for drugs as a result of being incarcerated, and (2) the use of multiple drugs simultaneously. They report the high number of newly released prisoner deaths reveal the need for effective drug treatment programs during incarceration and its continuation when prisoners are released to their respective communities. Where the second group is concerned, Ravndala and Amundsend (2010), and Davoli and colleagues (2007), reported that former drug treatment patients also face an elevated risk of death within the first four weeks of discharge since they are released into the same environments where they initially engaged in drug using behaviors. This period is critical because many relapse for a number of reasons, but face a high risk of death because of their lower tolerance for the drugs.

\section{The Public Health System's Epidemiological Approach to Preventing Opioid Abuse and Addiction}

Public health officials use the epidemiological approach which consists of health-event surveillance, epidemiological analysis, and intervention design and e valuation to focus on preventing illnesses and injuries (Schneider, 2011). Because of its proven success with treating and curing diseases, officials at the Centers for Disease Control and Prevention believe that the epidemiological approach can prevent drug abuse, including the use of illegal opioids and addiction with similar success. Opioids are defined as a class of drugs that include illicit heroin, but also prescription pain relievers such as oxycodone, hydrocodone, codeine, morphine, fentanyl and others (see National Institute of Drug Abuse, 2015). The epidemiological approach employs a multi-disciplinary effort to study and pre vent diseases and injuries that adversely impact the population. Because of the complexities of diseases and injuries, the approach draws on the resources of many 
disciplines to better understand and address the issues of drug use and addiction. Disciplines that are included in the epidemiological approach are as follows: biomedical sciences; environmental health sciences; social sciences; and the behavioral sciences (Schneider, 2011). Epidemiologists often use public education campaigns to reach millions of Americans. As such, they rely on television, radio, and billboards to inform and educate people about pressing health concerns (Schneider, 2011; Rosenberg and Fenley, 1991). They provide information on where to seek treatment and help for (in this case) drug addiction and opioid abuse. Moreover, this approach allows public health officials to treat diseases and injuries as epidemics when many people in the population are affected by it. As stated earlier, an estimated 20 to 25 million people in the U.S. either abuse or are addicted to opioids. Nevertheless, the epidemiological approach allows public health officials to mobilize resources in medicine, mental health, social sciences, and substance abuse services to prevent injuries and death (Rosenberg and Fenley, 1991). Therefore, epidemiologists represent a coalition of professions united by their shared mission and focus on disease prevention and health promotion. As part of its prevention efforts, epidemiologists look for common exposures and shared characteristics in the people who are sick or affected by drug use and addiction in order to seek causative measures.

\subsection{Prevention and Intervention}

Epidemiologists believe prevention comes through intervention after a problem has been identified by either the assessment process of a public health agency or through community concerns (e.g., when opioid abuse and addiction are discovered). The public health system uses several intervention methods: primary prevention, secondary prevention, and tertiary prevention. First, primary prevention seeks to avoid the occurrence of an illness or injury by preventing exposure to risk factors (e.g., preventing the occurrence of the act by being proactive in educating parents, children, schools, and the community at-large about the dangers of opioid abuse and addiction). Secondary prevention seeks to minimize the severity of the illness or injury-causing events once the event has occurred (e.g., removing users or addicts from the lifestyle and getting them treatment and counseling for their drug abuse and addiction). Third, tertiary prevention seeks to minimize disability by providing medical care and rehabilitation services (e.g., recovery and treatment centers and medical services) (Schneider, 2011). Epidemiologists view an injury as the result of a "chain of causation" involving an agent, a host, and the environment (Braithwaite, Taylor \& Treadwell, 2009). At times, the quality of tertiary intervention directly affects the success of primary intervention efforts. For example, rehabilitation efforts of opioid abusers should include providing them with alternative means of pain relief, coping, and a reassessed intrinsic sense of self-worth. Without these, abusers and addicts could easily relapse, overdose, or return to crime and drug use. This is especially true for those addicted to opioids, and engage in crime to support their addiction.

Epidemiologists believe that prevention is achieved by breaking the chain of causation at any step (Schneider, 2011). In the case of opioid abuse and addiction, it could be achieved by arresting the offenders who buy drugs, and later offering treatment in an attempt to prevent the continuation of the behavior and to alleviate the pain and suffering associated with the behavior. Moreover, it could also occur if drug abusers voluntarily seek help from an addiction clinic or recovery center. When epidemiologists study patterns of diseases and injuries in human populations and the causative factors that influence these patterns, they may detect signals of an emerging epidemic. Some questions that epidemiologists typically ask are who, when, and where. They are concerned with: First, who is being injured or contracting the disease (drug addiction) under investigation? Second, when is the injury or disease occurring? Third, where is the injury or disease occurring?

After analyzing all available data, epidemiologists are positioned to make better decisions about why the injury or disease is occurring. Their main goal is to use these data to prevent the spread of opioid abuse and addiction. Stated another way, public health officials believe it is more important to determine why people become involved in opioid use and abuse along with providing strategies to reduce the risk factors that lead to the behavior. Since labeling and conflict theories suggest that, during the drug war of the 1980s and 1990s, negative social processing, along with punitive measures used by the criminal justice system eventually proved to be counterproductive in reducing and eliminating drug use and addiction. As such, epidemiologists are unimpressed with the idea of relying solely on punitive approaches that have a past history of failure that resulted in historic numbers of drug users sent to prisons with lengthy sentences. Public health officials believe the negative labels given to drug abusers and addicts from being officially processed by the justice system invariably led to recidivism. As such, they argue that treatment and rehabilitation should help lead former drug abusers and addicts to successful reintegration back into society. Therefore, public health officials closely examine the structural aspects found among opioid abusers and engage in massive educational campaigns in addicts' respective communities to isolate factors that are more likely to influence more drug use. We support this view from epidemiologists and public health officials and argue that opioid abuse can be prevented in the U.S. if users are detected and receive extensive treatment.

Public health officials view the current incidents of opioid abuse and addiction in the U.S. as a public health crisis since an estimated 25 to 30 million Americans suffer from this problem. While there are many negative health consequences 
associated with opioid abuse and addiction, some include the following: liver damage, brain damage, severe respiratory depression, low blood volume, dysphoria, allergy-enhanced hypotensive effects, tremors, muscle twitches, convulsions, depression, dilated pupils, hyperactive reflexes, and premature deaths (Harvey et al., 1992). Therefore, these require treatment and health care, and in many cases, hospitalization. In essence, they require a response that goes beyond the resources provided by the criminal justice system.

\section{Conclusion}

Because the opioid epidemic is being fought using both criminal justice and public health strategies, we believe the results will prove effective given the many salient lessons learned from the crack cocaine war of the 1980s and 1990s. Chief among them have been that the United States cannot simply build its way out of a drug epidemic as revealed by its massive efforts to incarcerate and imprison shocking numbers of crack cocaine drug users and addicts with the consequence resulting in more people in the history of the American penal system arrested and warehoused (mostly under mandatory minimum sentencing guidelines that invariably helped to further destabilized many minority communities essentially leaving them in shambles owing in part to a lack of male providers, potential fathers, and informal controls needed to restrain community behavior), as well as generating astronomical correctional costs nationwide. Consequently, efforts have been made to reform the criminal justice system by developing strategies to decongest the nation's prisons, especially for offenders convicted under what is now viewed as discriminatory drug laws that also targeted nonviolent offenders. Today, more Americans than ever support the use of community based correctional programs rather than penal institutions that fail to rehabilitate or reform offenders along with having a dismal record of success at reducing recidivism. Unlike before, a majority of Americans believe that incarcerating offenders in general, but drug addicts in particular, is not enough to address the root cause of their behavior. They also believe that opioid addiction is a disease that requires treatment, therapy, and rehabilitation programs. We believe that the efforts of ordinary citizens alone cannot defeat drug addiction, but healthcare experts can be instrumental in helping. For example, though it may be challenging given the unbelievable numbers of opioid prescriptions that are written each year by physicians, we call on the American Medical Association (AMA) to be more vigilant in providing oversight into monitoring doctors with a history of over prescribing opioids. This may not be an easy task since patients ' privacy rights prevent others from knowing who is prescribing what to a patient. Stated differently, the challenge is twofold: First, doctors do not share patients' personal data on the same system or network. Second, opioid addicts who shop around for doctors are certainly not likely to inform potential prescription writers about what has already been prescribed to them by other doctors.

We believe that the nation's pharmacists can play a critical role in helping to prevent the overabundance of prescription filling. Since they fill prescriptions, pharmacists are in a better position to store information on what a patient is prescribed, how often prescriptions are filled, and who prescribes them. As such, they can monitor and report abuses to the states' attorney general or to the AMA. Apart from this, we argue that drug offenders who engage in violent crimes should receive institutional corrections if they pose a grave threat to the safety of their respective community. In the end, we advance the use of both criminal justice and public health strategies to prevent the spread and continuation of opioid use and addiction in America, but we do so for different reasons that include: the deterrent effect that the criminal justice system can bring, and the compassion of the public health approach in recognizing addiction as a disease, educating the general public about the dangers of opioid use and addiction, and where to seek treatment and prevention help. We believe this twin approach can help to negate the negative effects of labeling since in most cases, the majority of addicts will bypass the criminal justice system and make their way to addiction and recovery centers.

\section{References}

Alexander, E. (2001). What's wrong with the ACA? American Civil Liberties Union Foundation, The National Prison Project Journal, 1-28. Washington, DC.

Bachman, R. D., Schutt, R. K., \& Plass, P. S. (2017). Fundamentals of research in criminology and criminal justice: With selected readings Thousand Oaks, CA: Sage.

Barkan, S. E. (2009). Criminology: A sociological understanding ( $3^{\text {rd }}$ ed.). Upper Saddle River, NJ: Pearson/Prentice-Hall.

Bartley, E., \& Fillingim, R. (2013). Sex differences in pain: a brief review of clinical and experimental findings. BJA: British Journal of Anaesthesia, 111(1), 52-58. https://doi.org/10.1093/bja/aet127

Beck, A. J., \& Mumola, C. J. (1999). Prisoners in 1998 (Bureau of Justice Statistics Bulletin, NCJ 181643). Washington, DC: U.S. Department of Justice.

Becker, H. S. (1963). Outsiders: Studies in the sociology of deviance. New York: Free Press.

Beirne, P., \& Messerchmidt, J. W. (1995). Criminology $\left(2^{\text {nd }}\right.$ ed). Ft. Worth: Harcourt Brace Jovanovich. 
Bennett, W. J., DiluLio, J. J., \& Walters, J. P. (1996). Body count: Moral poverty and how to win American's war against crime and drugs. Simon \& Schuster.

Bernard, T. (1981). The distinction conflict and radical criminology. Journal of Criminal Law and Criminology, 72(1), 362-379. https://doi.org/10.2307/1142914

BJS. (1996). Correctional populations in the United States, 1996. U.S. Department of Justice. Office of Justice Programs.

BJS. (1999). Prisoners in 1999. https://www.bjs.gov/index.cfm.

Blumstein, A. (1993). Racial disproportionality in the U.S. prison population revisited. University of Colorado Law Review, 64, 743-760.

Blumstein, A., \& Beck, A. (1999). Population growth in U.S. prisons, 1980-1996. Crime and Justice, 26, 17-61. https://doi.org/10.1086/449294

Braithwaite, R. L., Taylor, S. E., \& Treadwell, H. M. (2009). Health issues in the black community ( ${ }^{\text {rd }}$ ed.). San Francisco, CA: Jossey-Bass Publications.

Brown, S. E., Ebensen, F. A., \& Geis, G. (2004). Criminology: Explaining crime and its context. (5 ${ }^{\text {th }}$ ed.). Cincinnati, $\mathrm{OH}$ : Anderson Publishing.

Cohen, M., R. R., \& Steen, S. (2003). Measuring Public Perceptions of Appropriate Sentences, Executive Summary. Report prepared for U.S. Department of Justice.

Cork, D. (1999). Examining space-time interaction in city-level homicide data: Crack markets and the diffusion of guns among youth. Journal of Quantitative Criminology, 15, 379-406. https://doi.org/10.1023/A:1007540007803

Davoli, M., Bargagli, A. M., Perucci, C. A., Schifano, P., Belleudi, V., Hickman, M.,...Faggiano, F. (2007). Risk of fatal overdose during and after specialist drug treatment: The VEdeTTE study, a national multi-site prospective cohort study. Addiction, 102(12), 1954-1959. https://doi.org/10.1111/j.1360-0443.2007.02025.x

Degenhardt, L., Bucello, C., Mathers, B., Briegleb, C., Ali, H., Hickman, M., \& McLaren, J. (2011). Mortality among regular or dependent users of heroin and other opioids: a systematic review and meta-analysis of cohort studies. Addiction, 106(1), 32-51.https://doi.org/10.1111/j.1360-0443.2010.03140.x

Donziger, S. R. (1996). The real war on crime: The report of the national criminal justice commission. New York, NY: Harper-Perennial.

Drug Enforcement Administration. (1988). Crack cocaine availability and trafficking in the United States. Washington, D.C. U.S. Department of Justice, Drug Enforcement Administration, Cocaine Investigation.

Elkins, C. (2015). Hooked on Pharmaceuticals: Prescription Drug Abuse in the World. Drugwatch.com. Downloaded $12 / 09 / 2016$ from https://www.drugwatch.com/2015/08/10/worldwide-prescription-drug-abuse/

Fagan, J. E. (1996). Gangs, drugs, and neighborhood change. In gangs in America, 2d ed., edited by C.R.Huff. Thousand, Oaks, CA: Sage Publications (pp.39-74).

Fillingim, R., King, C., Ribeiro-Dasilva, M., Rahim-Williams, B., \& Riley, J. (2009). Sex, Gender, and Pain: A Review of Recent Clinical and Experimental Findings. The Journal of Pain : Official Journal of the American Pain Society, 10(5), 447-485. https://doi.org/10.1016/j.jpain.2008.12.001

Goffman, E. (1963). Stigma: Notes on the management of spoiled identity. Englewood Cliffs, NJ: Prentice-Hall.

Grzelewski, J. (2015). Consider paradigm shift in interactions of police with heroin, opioid addicts. http://www.vindy.com/news/2015/nov/09/

Hagan, F. E. (2014). Research methods in criminal justice and criminology ( $9^{\text {th }}$ ed.). Upper Saddle River, CA: Pearson.

Hagedorn, J. M. (1988). People and folks: Gangs, crime and the underclass in a rustbelt city. Chicago, IL: Lakeview Press.

Harvey, R. A., Champe, P. C., Mycek, M. J., Gertner, S. B., \& Perper, M. M. (1992). Lippincott's Illustrated Reviews: Pharmacology. New York, J.B. Lippincott Company.

Hendricks, L., \& Wilson, A. (2013). The impact of crack cocaine on Black America. National Forum Journal of Counseling and Addiction, 2(1), 1-6.

Hurley, R., \& Adams, M. (2008). Sex, gender, and pain: an overview of a complex field. Anesth Analg,107(1), 309-317. https://doi.org/10.1213/01.ane.0b013e31816ba437 
IMS Health. N. D. National Prescription Audit (NPATM). Cited in internal document: Preliminary Update on Opioid Pain Reliever (OPR) Prescription Rates Nationally and by State: 2010-2013.

Jenkins, P. (1984). Crime and Justice: Issues and ideas. Belmont, CA: Brooks/Cole Publishing Company.

Johnston, L., O’Malley, P., Bachman, J., \& Schulenberg, E. (2011). Monitoring the future national survey results on drug use, 1975-2010: Volume II, College students and adults ages 19-50. Ann Arbor: Institute for Social Research, The University of Michigan.

Jones C., Mack K., \& Paulozzi, J. (2013). Pharmaceutical overdose deaths, United States, 2010. JAMA, 309, 657-659. https://doi.org/10.1001/jama.2013.272

Kaeble, D., \& Glaze, L. (2016). Correctional populations in the United States, 2015. BJS, U.S. Department of Justice, Office of Justice Programs.

Kim, H., Windsor, T., \& Mareiniss, D. The Opioid Epidemic in the United States. Emergency Medicine Clinics of North America, 34(2), e1-e23.

Kocherlakota, P. (2014). Neonatal Abstinence Syndrome. Pediatrics, 134(2). Accessed at https://doi.org/10.1542/peds.2013-3524

Krisberg, B., Craine, J., \& Machionna, S. (2004). Attitudes of Californians Toward Effective Correctional Policies (FOCUS). National Council on Crime and Delinquency (NCCD).

Kuhn, T. S. (1970). The structure of scientific revolutions ( $2^{\text {nd }}$ ed.). Chicago, IL: University of Chicago Press.

Last, J. (Ed.). (2001). A dictionary of epidemiology (4th ed.). Oxford University Press: New York.

Lev, R., Lee, O., Petro, S., Lucas, J., Castillo, E., Vilke, G., \& Coyne, C. (2016). Who is prescribing controlled medications to patients who die of prescription drug abuse? The American Journal of Emergency Medicine, 34(1), 30-35. https://doi.org/10.1016/j.ajem.2015.09.003

Lynch, M. J., \& Groves, W. B. (1989). A primer in Radical Criminology ( $2^{\text {nd }}$ ed.). Albany, N.Y.: Harrow and Heston Press.

Mauer, M. (1999). The race to incarcerate. New York: The New Press.

Maxfield, M. G., \& Babbie, E. R. (2011). Research methods for criminal justice and criminology (6 $6^{\text {th }}$ ed.). Belmont, CA: Wadsworth.

McDonald, D., \& Carlson, K. (2013). Estimating the prevalence of opioid diversion by "doctor shoppers" in the United States. PLoS One, 8(7), e69241. https://doi.org/10.1371/journal.pone.0069241

Merrall, E., Kariminia, A., Binswanger, I., Hobbs, M., Farrell, M., Marsden, J., Hutchinson, S., Bird, S. (2010). Meta-analysis of drug-related deaths soon after release from prison. Addiction, 105(9), 1545-1554. https://doi.org/10.1111/j.1360-0443.2010.02990.x

Messner, S. F., \& Rosenfeld, R. (2007). Crime and the American dream ( $4^{\text {th }}$ ed.). Belmont, CA: Thomson Wadsworth.

Michalowski, R. J. (1985). Order, law, and crime: An introduction to criminology. New York: Random House.

Muhuri, K., Gfroerer, C., \& Davies, C. (2013). Associations of nonmedical pain reliever use and initiation of heroin use in the United States. US Department of Health and Human Services: Substance Abuse and Mental Health Services Administration, Center for Behavioral Health Statistics and Quality Data Review.

National Association of Drug Diversion Investigators. (2011). What exactly is drug diversion? http://www.naddi.org/aws/NADDI/pt/sd/news_article/43411/_PARENT/layout_details/false

National Center for State Courts. (2006). The NCSU Sentencing Attitudes Survey: A report on the findings. Princeton survey research associates international for the national center for state courts. www.ncsconline.org.

National Institute of Drug Abuse. (2015). Drugs of Abuse: Opioids. Bethesda, MD: National Institute on Drug Abuse. Available at http://www.drugabuse.gov/drugs-abuse/opiods.

National Institute on Drug Abuse. (2015). Dramatic Increases in Maternal Opioid Use and Neonatal Abstinence Syndrome.

https://www.drugabuse.gov/related-topics/trends-statistics/infographics/dramatic-increases-in-maternal-opioid-useneonatal-abstinence-syndrome

National Institute on Drug Abuse; National Institutes of Health; U.S. Department of Health and Human Services. (2016). Monitoring the Future 2015 Survey Results: Abuse of Prescription (Rx) Drugs Affects Young Adults Most. https://www.drugabuse.gov/related-topics/trends-statistics/infographics/abuse-prescription-rx-drugs-affects-young- 
adults-most

National Pharmaceutical Council. (2001). Pain: Current Understanding of Assessment, Management, and Treatments.

Ødegard, E., Amundsen, E. J., Kielland, K. B., \& Kristofferson, R. (2010). The contribution of imprisonment and release to fatal overdose among a cohort of Norwegian drug abusers. Addiction Research \& Theory, 18(1), 51-58.

Payne, B. K., Oliver, W. M., \& Marion, N. E. (2016). Introduction to criminal justice: A balanced approach. Thousand Oaks, CA: Sage.

Pew Charitable Trusts. (2012). Time served: The high cost, low return of long prison terms, http://www.pewtrusts.org/en/research-and-analysis/fact-sheets/2013/10/08/prison-time-served-and-recidivism.

Potter, G. W., \& Kappeler, V. E. (1996). Constructing crime: Perspectives on making news and social problems. Prospect Heights, IL: Waveland Press.

Purdue Pharma. (1999). OxyContin Marketing Plan, 2001.

Ravndala, E., \& Amundsenb, E. (2010). Mortality among drug users after discharge from inpatient treatment: An 8-year prospective study. Drug and Alcohol Dependence, 108(1-2), 65-69. https://doi.org/10.1016/j.drugalcdep.2009.11.008

Reinarman, C., \& Levine, H. G. (1989). Crack in Context: Politics and media in the making of a drug scare. Contemporary Drug Problems, 16(4), 535-577.

Risser, J. M., Timpson, S. C., McCurdy, S. A., Ross, M. W., \& Williams, M. L. (2006). Psychological correlates of trading sex for money among African American crack cocaine smokers. The American Journal of Drug and Alcohol Abuse, 32(4), 645-653. https://doi.org/10.1080/00952990600919062

Rosenberg, M. L., \& Fenley, M. A. (1991). Violence in America: A public health approach. New York: Oxford Uni versity Press.

Schneider, M. J. (2011). Introduction to public health (3 ${ }^{\text {rd }}$ ed.). Sudbury, MA: Jones and Barlett Publishers.

Schram, P. J., \& Tibbetts, S. G. (2014). Introduction to Criminology. Thousand Oaks, CA: Sage.

Sentencing Reform and Corrections Act of 2016.

Shaefer, M. K., \& Perz, J. F. (2014). Outbreaks of infections associated with drug diversion by US health care personnel. Mayo Clinic Proceedings, 89(7), 878+. Retrieved from

http://go.galegroup.com/ps/i.do?p=HRCA\&sw=w\&u=gree96177\&v=2.1\&it=r\&id=GALE\%7CA377665578\&sid= summon\&asid=e4cb3d00c86535b28251297f31e5e 808

Shank, S. E., \& Haugen, S. E. (1987). The employment situation during 1986: job gains continue, unemployment dips. Monthly Labor Report, 1-10.

Siegel, L. J. (2015). Criminology ( $9^{\text {th }}$ ed.). Belmont, CA: Wadsworth/Cengage Learning.

Strand, J. (2016). Opioid crisis demands paradigm shift. http://hpr1.com/index.php/feature/news/.

Substance Abuse and Mental Health Services Association. (2016). Opioids. http://www.samhsa.gov/atod/opioids

Surette, R. (1995). Predatory criminals as media icons. In G. Barak (Ed.). Media, Process, and the Social Construction of Crime (pp. 131-158). New York: Garland Publishing.

Surette, R. (1998). Media, crime, and criminal justice: Images and realities ( ${ }^{\text {nd }}$ ed.). Pacific Grove, CA: Brooks/Cole.

Survey on Drug Abuse and Drug Policy: Summary of Results. (2001). Ridder/Braden, INc.

Tannenbaum, F. (1938). Crime and the Community. Boston, MA: Ginn.

The Sentencing Project. (2016). U.S. Prison Population Trends 1999-2014: Broad variations among states in recent years. Washington, D.C.

Tonry, M., \& Wilson, J. Q. (1990). Drugs and Crime. Chicago, IL: The University of Chigo Press.

U.S. Department of Health and Human Services (January, 2015). Opioid painkillers widely prescribed among reproductive age women. http://www.cdc.gov/media/releases/2015/p0122-pregnancy-opioids.html.

U.S. Department of Health and Human Services. (2013). Centers for Disease Control and Prevention, 2013. WONDER [database]. Centers for Disease Control and Prevention: Atlanta, GA

U.S. Department of Health and Human Services. (2015). Increases in Drug and Opioid Overdose Deaths — United States, 2000-2014. Morbidity and Mortality Weekly Report; 64; 1-5. Centers for Disease Control and Prevention. 
U.S. Department of Health and Human Services. (2015). Today's Heroin Epidemic Infographics. http://www.cdc.gov/vitalsigns/heroin/infographic.html

U.S. Department of Health and Human Services. (2016). Centers for Disease Control and Prevention, 2016. WONDER [database]. Centers for Disease Control and Prevention: Atlanta, GA. Available at http://wonder.cdc.gov).

U.S. Department of Health and Human Services. (2016). Drug overdose deaths in the United States hit record numbers in 2014. http://www.cdc.gov/drugoverdose/epidemic/index.html.

U.S. Department of Health and Human Services. (2016). Risk Factors for Prescription Opioid Abuse and Overdose. http://www.cdc.gov/drugoverdose/opioids/prescribed.html.

U.S. Government Accounting Office. (2003). Prescription Drugs: OxyContin Abuse and Diversion and Efforts to Address the Problem. Highlights of a Government Report, GAO-04-110, 109-113. U.S. Government Accounting Office: Washington, DC.

United Nations Office on Drugs and Crime. (2011). World Drug Report 2011. New York City: United Nations.

United Nations Office on Drugs and Crime. (2012). World Drug Report 2012 (United Nations publication, Sales No. E.12.XI.1).

United Nations Office on Drugs and Crime. (2016). World Drug Report 2016 (United Nations publication, Sales No. E.16.XI.7).

Van Zee, A. (2009). The Promotion and Marketing of OxyContin: Commercial Triumph, Public Health Tragedy. American Journal of Public Health, 99(2), 221-227. https://doi.org/10.2105/AJPH.2007.131714

Vimont, C. (2014). New Paradigm Addiction Recovery Model Takes Long Term View. http://www.drugfree.org/news-service.

Walker, S. (1998). Sense and nonsense about crime and drugs: A policy-guide $\left(4^{\text {th }}\right.$ ed.). Belmont, CA: West/Wadsworth Publishing Company.

Walmsley, R. (2015). The sentencing project. Trends in U.S. corrections: U.S. state and federal Prison Populations, 1925-2014. Washington, DC. Fact Sheet: Trends in U.S. Corrections.

Wilson, W. J. (1996). When work disappears. New York, NY: Alfred A. Knopf.

\section{Copyrights}

Copyright for this article is retained by the author(s), with first publication rights granted to the journal.

This is an open-access article distributed under the terms and conditions of the Creative Commons Attribution license which permits unrestricted use, distribution, and reproduction in any medium, provided the original work is properly cited. 